\title{
Imprinting in guinea pigs
}

\section{MICHAEL G. GASTON, ROBERT STOUT, and ROLAND TOM, California State College at Los Angeles, Calif. 90032}

Guinea pig pups were removed from their sow immediately after delivery and given following response (FR) training in a circular runway every $2 \mathrm{~h}$ over the first day after birth. $A$ variety of imprinting objects were employed. Ss were subsequently given preference trials wherein the original lure was pitted against novel stimuli. Every pup developed a FR to the moving lure and, in choice testing, followed that object in preference to competing stimuli. These observations provided a clear-cut demonstration of classical imprinting in a mammal.

Over the past decade the number of experimental investigations of imprinting has increased at a positively accelerated rate. For several species of precocial birds, it has been demonstrated that if they are exposed to a moving lure during a critical period early in their lives they will develop a relatively permanent attachment to that object. However, despite the bulk of the literature, there were only scattered anecdotal reports of imprinting in mammals (Thorpe, 1963; Sluckin, 1965). Hess (1959) reported having observed the following response (FR) in guinea pigs, but his procedures were nonstandardized and this preliminary work apparently has not been pursued further. More recently, Shipley (1963) conducted an experimental investigation of imprinting in this species. He studied social responses made to a white block which moved back-and-forth across a small compartment. These responses included "... sniffing, licking, and contact seeking; and typical courtship and mating reactions such as mounting, face washing and pointing ... The dependent variable was simply the number of bouts of social behavior described above that occurred during the five-minute testing sessions [p. 471]."

Although there is no universally accepted set of operations which defines imprinting, it has typically been inferred from two sorts of behavior: (1) the animal develops a FR to moving lure, and/or (2) the animal chooses to be near an object to which it was exposed during the critical period in preference to a novel object. Whether Shipley demonstrated imprinting in guinea pigs depends upon whether we are willing to accept social responses as criteria; however, it is clear that he did not demonstrate "classical" imprinting. The notion of imprinting implies that whatever social responses are directed toward an object will be specific-that the attachment will persist when other stimuli are subsequently introduced in competition with the original object. The purpose of the present investigation was to show that guinea pig pups would develop a FR in response to a moving lure and would, on later choice trials, follow that object in preference to novel stimuli.

\section{Subjects}

\section{METHOD}

The Ss were 18 Hartly and Prubian guinea pig pups which were removed from the sow within an hour after birth and raised in darkened and partially sound-proofed pens. They were fed a diet of oats, pablum, and hand-fed a nursing formula of five parts water to one part condensed milk. This diet was supplemented with rock salt and vitamin $\mathrm{C}$.

Apparatus and Procedure

The imprinting apparatus was a circular runway, 18 in. wide and $150 \mathrm{in}$. in circumference at the center. Stripes on the floor divided the alley into five equal segments. The imprinting objects were suspended from a radiating arm which was attached to a variable-speed motor. A variety of lures were employed: a 11/2-in. blue rubber ball, a 11/2-in. red plastic ball which contained bells that jingled when the ball was dragged along the floor, a 4-in. square block of wood, a toy stuffed dog (approximately 6 in. long), and, finally, an 8-in. lighted flashlight. During preference testing, the original lure was pitted against at least two of the remaining stimulus objects. Inasmuch as there was no discernible difference in the efficacy of these objects in eliciting the FR during either original training or choice testing, details of the combinations of lures employed for different Ss will not be described.

The procedure during imprinting was to place a pup 6 in. from an object which, 1 min later, began to move around the alley. The speed of rotation was adjusted somewhat for individual Ss, but averaged about $2.5 \mathrm{in} . / \mathrm{sec}$. Each $\mathrm{S}$ was given an imprinting session every $2 \mathrm{~h}$ over the first day of life. As a measure of the strength of following, a pup was awarded a point for each $30 \mathrm{in}$. it remained (as estimated by the 0 ) within 6 in. of the moving lure. An imprinting session lasted $10 \mathrm{~min}$ or until an $\mathrm{S}$ had accumulated five points. In the preference tests, the object on which $S$ had received following training and one of the novel objects were suspended side-by-side, one along the inside of the alley, the other on the outside-the positions being randomly determined. Again, an S was awarded one point for each $30 \mathrm{in}$. he followed an object; no points were given if he followed between the stimuli. A test session was terminated when the $S$ had accumulated five points on a given object. Five Ss were tested on Days 2, 3, and 4 following birth; four were tested on Days 3, 4, and 5; three were tested on Days 2 and 5; two were tested on Days 2, 4, and 7; two Ss received preference tests on Days 7, 14, and 17. Two Ss who received FR training died before they could be run in the preference tests.

\section{RESULTS AND DISCUSSION}

As shown in Fig. 1, by the end of the first day of life every $S$ had attained our arbitrary criterion for acquisition of the FR. There was slow growth of following during the first $18 \mathrm{~h}$, after which time performance improved rapidly. How much of

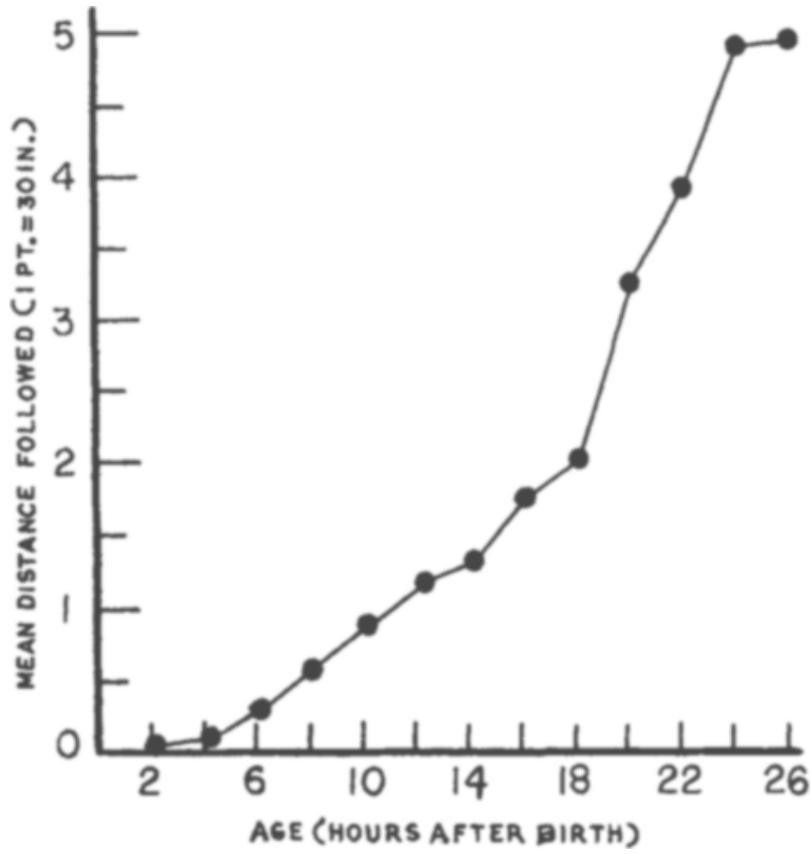

Fig. 1. Strength of the following response as a function of hours after birth. A training session lasted $10 \mathrm{~min}$ or until $\mathrm{S}$ had accumulated 5 points (followed 150 in.). 
this improvement was due to a critical period, maturation, or simply practice cannot be ascertained from the present data. In order to demonstrate a critical period it would have been necessary to initiate training at different ages for separate groups of animals. Results of the preference testing indicated quite convincingly that the attachment which pups developed for the moving lure during FR training was durable and specific for that object. All 16 animals tested displayed a marked preference for the familiar stimulus, following it sufficiently to gain five points. In no instance did an S follow the novel lure long enough to earn a point. Such a profound difference made statistical analysis superfluous. Had the objects not been in close proximity, it is possible that more following would have been directed toward the novel object. Under the present procedure, an animal could easily view the test object while following the original lure.

We frankly were surprised at the readiness with which the guinea pigs evidenced the FR during training and preference for the familiar object in the choice tests. This study was undertaken simply as an attempt to provide a clear-cut demonstration of imprinting in a mammal, hence we had not anticipated how fruitful additional quantification would have been. In work subsequent to this we tried to mitigate the rigors entailed by all-night vigils awaiting birth of the pups and hand-nursing them afterward. When, however, we allowed pups to stay with the sow after they were born their FR performance was markedly inferior; and, in another study, such nonisolated pups failed to imprint to visual flicker-a phenomenon which has been shown to occur in birds (James, 1959). Still, the importance of social isolation in guinea pigs is not clear, since Shipley (1963) found strong evidence for the attachment of social responses in pups reared with their mother for five days.
There has been considerable controversy concerning whether, and the degree to which, imprinting differs in mechanism from associative learning. Much recent work (Moltz, 1963) has shown that the differences are not as great as Lorenz (1937) initially posited. Since nearly all experimental work in learning has involved mammals, the guinea pig would seem to be especially suited as an $S$ in investigations designed to further elucidate the relationship between imprinting and learning. There is a dearth of evidence regarding the neurophysiological substrate of imprinting; certainly, the technical difficulties attendant to surgical manipulations of newly hatched birds are great. Again, the guinea pig would seem far more suitable for such studies, and the fact that he is a mammal would lend relevance of the results to those obtained in physiological investigations of learning.

\section{REFERENCES}

HESS, E. H. Imprinting. Science, 1959, 130, 133-141.

JAMES, H. Flicker: An unconditioned stimulus for imprinting. Canadian Journal of Psychology, 1959, 13, 59-67.

LORENZ, K. The companion in the bird's world. Auk, 1937, 54, 245-273.

MOLTZ, H. Imprinting: An epigenetic approach. Psychological Review, 1963, 70, 123-138.

SHIPLEY, W. U. The demonstration in the domestic guinea pig of a process resembling classical imprinting. Animal Behaviour, 1963, 11, 470-474.

SLUCKIN, W. Imprinting and early learning. Chicago: Aldine, 1965.

THORPE, W. H. Learning and instinct in animals. (2nd ed.) London: Methuen, 1963. 